\title{
Estudo etnográfico da satisfação do usuário do Programa de Saúde da Família (PSF) na Bahia
}

\author{
Ethnography study about user satisfaction \\ of Family Health Program in Bahia
}

Leny Alves Bomfim Trad 1

Ana Cecília de Souza Bastos 2

Edyara de Morais Santana 1

Mônica Oliveira Nunes 1

Este artigo contou com apoio financeiro do $\mathrm{CNPq}$, Banco Mundial

e Ministério da Saúde.

1 Instituto de Saúde

Coletiva da Universidade

Federal da Bahia.

Rua P. Feijó 29, Canela.

40110-170, Salvador BA.

trad@ufba.br

2 Faculdade de Filosofia

e Ciências Humanas,

Universidade Federal

da Bahia.
Abstract The present study consists of a qualitative evaluation of user satisfaction in the areas covered by the Family Health Program, which are located within five municipalities of Salvador (Bahia, Brazil). During the evaluation, the following dimensions were taken into account: cognitive, relational, organizational and professional; the family health teams' point of view was also considered. Owing to criticism directed in the literature towards the methodological limitations of studies undertaking to evaluate user satisfaction, in particular biases linked to social expectations or to the reduction of the subjective process of evaluation through yes/no-type answers to sets of closed questions, we favored in this case methodological strategies that bear the hallmark of ethnography. Through the focal groups technique, the users have been able to express their perception of the program and of the services offered by the teams while they were disclosing their needs and the satisfactions they expected from them.

Key words Ethnography, User satisfaction, Health programs
Resumo O presente estudo consiste em uma avaliação qualitativa de satisfação de usuários em áreas cobertas pelo Programa de Saúde da Família/PSF, situadas em cinco municípios da Bahia. Foram consideradas nesta avaliação as seguintes dimensões: cognitiva, relacional, organizacional e profissional; vistas também sob o ponto de vista das equipes de saúde da família. Tendo em vista as críticas apontadas pela literatura quanto às limitações metodológicas em estudos que avaliam a satisfação de usuários, notadamente vieses ligados à desejabilidade social ou à redução do processo subjetivo de avaliação a respostas do tipo sim/não em questionários fechados, privilegiamos neste caso estratégias metodológicas de cunho etnográfico. A partir da técnica de grupos focais, os usuários expressaram sua percepção sobre o programa e os serviços oferecidos pelas equipes, ao tempo que revelavam suas necessidades e expectativas de satisfação das mesmas. Palavras-chave Etnografia, Satisfação de usuários, Programa de saúde 


\section{Introdução}

O fortalecimento do controle social no âmbito do SUS e o incentivo à participação comunitária pressupõem uma concepção do usuário do sistema de saúde com competência para avaliar e intervir modificando o próprio sistema. Prévost, Fafard, \& Nadeau (1998), com base em ampla revisão da literatura, situam o aumento do interesse pela avaliação da satisfação dos usuários em inícios dos anos 70. Segundo Ware et al. (1983) a medida da satisfação dos usuários ou dos pacientes é uma avaliação pessoal dos cuidados e dos serviços de saúde que são dispensados.

Outros autores, como Donabedian (1980) e Pascoe (1983), consideram que a satisfação dos usuários pode ser vista pela reação que têm diante do contexto, do processo, e do resultado global de sua experiência relativa a um serviço. Pascoe (1983) enfatiza ainda que essa avaliação se baseia em padrões subjetivos, implicando, portanto, atividades psicológicas (no campo perceptual) de ordem cognitiva e afetiva, engajadas em um processo comparativo entre a experiência vivida e critérios subjetivos do usuário.

Os elementos contemplados pelo sujeito na avaliação de níveis de satisfação envolvem uma ou mais combinações dos seguintes elementos: um ideal de serviço, uma noção de serviço merecido, uma média da experiência passada em situações de serviços similares, e um nível subjetivo mínimo da qualidade de serviços a alcançar para ser aceitável. Favaro e Ferris (1991 apud Prévost, Fafard e Nadeau 1998) concluem que abordar a satisfação dos usuários implica trazer um julgamento sobre características dos serviços $e$, portanto, sobre sua qualidade. Assim, a perspectiva do usuário fornece informação essencial para completar e equilibrar a qualidade dos serviços. Na mesma linha, Atkinson (1993) propunha que a avaliação sistemática da qualidade das ações dos serviços de saúde constitui-se uma medida de otimização dessas ações.

Além das características do usuário que avalia e dos focos de avaliação, a literatura destaca diferentes perspectivas metodológicas na abordagem da satisfação dos usuários de serviços de saúde. Em uma primeira perspectiva, Prévost, Fafard e Nadeau (1998) defendem o emprego de instrumentos rigorosamente validados e padronizados; indicam também a importância de se garantir, no processo de avaliação, a objetividade, o caráter confidencial e o anonimato dos entrevistados.
Os estudos de avaliação de satisfação de usuário utilizam, em geral, escalas e questionários compostos de subitens que tratam de uma ampla gama de questões, incluindo estrutura, funcionamento e avaliação do serviço de saúde pelo usuário. Têm-se limitado, porém, à mensuração do nível de satisfação com o serviço prestado, sem um esforço de contextualização cultural (Atkinson, 1993; Williams, 1994). Quando a experiência do usuário no sistema de saúde se reduz a uma pergunta dicotômica relacionada à satisfação ou insatisfação, deixam de ser contempladas considerações sobre as crenças, os modos de vida, as concepções do processo saúde-doença dos usuários do sistema de saúde, aspectos que claramente influenciam os modos de utilização dos serviços pelo usuário.

Visando superar essas limitações, o presente estudo desenvolveu uma avaliação de cunho etnográfico da satisfação de usuários do Programa de Saúde da Família em cinco municípios da Bahia. Destacamos como objetivos da pesquisa: 1) avaliar a satisfação de usuários do PSF nas dimensões relacional, organizacional e profissional; e 2) confrontar o ponto de vista de usuários e de profissionais das equipes.

\section{Metodologia}

O estudo estruturou-se a partir do desenvolvimento de grupos focais e, de forma complementar, de entrevistas com informantes privilegiados (escolhidos entre gestores e/ou membros da equipe do PSF). Nos cinco municípios investigados foram nove grupos focais com usuários e cinco com membros das equipes. Os grupos com usuários tinham entre dez a doze participantes de idades variadas, privilegiando-se as mulheres na composição dos mesmos. Em todos os grupos focais buscou-se incorporar moradores de diferentes micro-áreas e características sócio-demográficas e epidemiológicas.

$\mathrm{Na}$ seleção dos cinco municípios da Bahia (sucintamente descritos na tabela 1) contemplados no estudo, consideramos os requisitos: pelo menos um ano de implantação da estratégia de saúde da família (PSF ou PACS); e características sócio-demográficas diferenciadas. Vale dizer que os índices de cobertura do Programa de Saúde da Família (PSF) no estado da Bahia ainda são muito baixos. Em dezembro/2000, o PSF encontrava-se implantado apenas em 63 municípios contando com 249 equipes, contemplando aproximadamente 249.000 famílias 
(1.120.500 pessoas), atingindo uma cobertura inferior a $15 \%$.

Foram utilizadas técnicas de análise de conteúdo para interpretação dos dados, adotando as categorias baseadas nas dimensões propostas por Prévost et al.

- necessidades: carências referidas, demandas associadas com saúde;

- cognitiva: percepção sobre o programa, idéia central;

- relacional: respeito e consideração; escuta; compreensão; acolhida; gentileza por parte dos profissionais da equipe;

- organizacional: tempo de espera (por horário disponível e já no local de atendimento); horário de abertura e funcionamento; horário dos profissionais; localização dos serviços; acesso à informação;

- profissional: tempo dispensado; informações suficientes e claras; implicação da busca de soluções; qualidade ou competência; eficácia dos serviços; disponibilidade.

\section{Resultados e discussão}

Uma primeira observação de caráter geral refere-se à perspectiva das mulheres como avaliadoras de serviços de saúde, caracterizada pelo conhecimento ímpar do cotidiano e pelo fato de serem as principais agentes de saúde no contexto doméstico. Observa-se de fato que as mulheres são capazes de identificar com clareza indicadores de qualidade de vida e de melhoria de vida.

Em relação aos achados, chama a atenção o fato de que, embora tenhamos investigado cinco realidades distintas do ponto de vista cultural, social e demográfico, observamos uma grande similaridade nos dados encontrados, seja do ponto de vista das necessidades da população, seja quanto à avaliação do PSF. Este dado pode ser explicado pelo fato de que em todos os municípios estudados, seguindo uma tendência estadual e nacional, o PSF foi implantado nas áreas onde se concentram as populações mais pobres e com as piores condições de infra-estrutura básica.

\section{A dimensão cognitiva: o que pensam sobre o PSF}

Fica claro que não há uma identificação muito clara do programa como tal. O que conseguimos extrair dos relatos é uma associação temporal entre mudanças (visitas domiciliares, palestras, etc.), melhorias nos serviços de saúde e o período de implantação do PSF. Em quase todos os grupos focais, quando eram abordados inicialmente acerca do PSF surgiam perguntas como: "vocês tão falando do posto?" Ou, no melhor dos casos: "é sobre estes agentes que visitam as casas". Há uma dificuldade em visualizar o PSF ou identificar com precisão sua lógica de funcionamento. À exceção das mulheres mais velhas, que vêem de um modo mais abrangente, a avaliação adquire uma característica fragmentada, calcada mais em experiências particulares e menos em uma visão geral do funcionamento do PSF.

O programa, de fato, é muito mais identificado a partir da sua materialização em um Posto de Saúde e nas ações dos seus profissionais. É curioso que a referência à Unidade de Saúde de Família não apareceu em nenhum dos grupos focais. A alusão ao "posto" foi uma constante nos grupos. Nos casos, onde a unidade do PSF foi construída especialmente para este fim, parecia haver uma distinção mais clara entre "este tipo de serviço" e o anterior. Em realidade, uma das melhorias citadas associa-se à construção propriamente dita de um posto de saúde na área.

Tabela 1

Caracterização dos municípios - dados de 2000

\begin{tabular}{lcccccc}
\hline Município & População & Ano IM PSF & n equipes & n famílias & $\begin{array}{c}\text { Cobertura } \\
\text { PSF }\end{array}$ & $\begin{array}{c}\text { Cobertura } \\
\text { PACS }\end{array}$ \\
\hline A & 126.000 & 1998 & 02 & 1.600 & $5 \%$ & $55,14 \%$ \\
B & 145.000 & 1998 & 18 & 14.000 & $29 \%$ & $66,9 \%$ \\
C & 247.107 & 1998 & 04 & 3.536 & $5,2 \%$ & $43,87 \%$ \\
D & 109.236 & 1997 & 04 & 3.393 & $25,36 \%$ & $75,00 \%$ \\
E & 250.000 & 1998 & 28 & 24.293 & $9,45 \%$ & $65,37 \%$ \\
\hline
\end{tabular}


De modo geral, a ação do programa é valorizada a partir de uma série de melhorias instaurada na vida dos moradores do bairro e/ou das áreas atendidas. Ressaltando que em nenhum momento aparece claramente uma alusão ao termo PSF ou à estratégia de saúde da família. O parâmetro de referência para estas melhorias ou mudanças positivas são os "tempos mais antigos" (especialmente para os mais velhos).

E antes, quando eu cheguei aqui, não tinha um posto médico, agora tem; tem os agentes de saúde que eu acho muito legal, muito bom, que vai na casa da pessoa, né? Assim, quando pode, marca o médico pra gente, às vezes a gente tá trabalhando, não pode marcar, eles vão e marca, muito bom isso. (D)

\section{A dimensão relacional}

Não restam dúvidas de que os usuários expressam um alto grau de satisfação em relação à dimensão relacional, em todos os seus atributos: respeito, consideração, escuta, compreensão, acolhida, gentileza por parte dos profissionais da equipe. No bojo dessa satisfação, os profissionais mais destacados são os agentes de saúde e os médicos. Vale notar que os agentes são o primeiro dado concreto referido pelas famílias quando perguntadas sobre PSF; à exceção de Vitória da Conquista, onde os agentes não foram destacados nos grupos focais.

Os Agentes Comunitários de Saúde/ACS são identificados pelos usuários como alguém que desempenha o papel de mediador entre a comunidade e os profissionais de saúde. Ou seja, são valorizados pelo fácil trânsito que dispõem no sistema formal de atenção à saúde, o que torna menos árduo o processo de acesso ao cuidado.

Facilita sim, porque o médico só tem mais acesso ao doente com o agente. O agente é que éo comunicador pra levar o médico até o doente e isso tem acontecido. (Área rural C)

E esses dias mesmo, meu esposo estava com problema de recuperação, aí eu conversei com o B., ele foi lá no posto, conversou com o médico, o médico marcou o horário, ele foi, chegou lá deram uma ficha pra ele (...). (D)

A isso se somam várias ações associadas à figura do agente e relacionadas com disponibilidade, acolhida e compreensão acerca das necessidades da comunidade.

Na minha casa, ele chega normalmente e pergunta se tem alguém com algum tipo de problema de saúde.
Lá em casa quando ele chega e eu tô, ele entra, parte pra um papinho: 'Tá tudo bem, Dona M.?' 'Mais ou menos', 'Qualquer coisa me procure, 'Tá bom'. (A)

D. é uma maravilha, não se fala mais, ela vai todo dia lá em casa (..) E o que eu acho mais maravilhoso é o atendimento das pessoas com a gente. (..) D. é muito educada, é muito atenciosa. (D)

$\mathrm{O}$ fato de ser um morador da comunidade facilita o trânsito do agente entre as famílias o agente sabe o que a gente precisa porque vive aqui. Por outro lado, este é o profissional da equipe mais "controlado" pela comunidade. $\mathrm{Na}$ maioria dos municípios, observa-se que a população das áreas adstritas acompanha atentamente o desempenho dos ACS, se cumprem os horários, as rotinas, quando descansam, quando faltam ao trabalho. Um outro dado associado com a pertença dos ACS ao bairro é a interferência de outras esferas de relacionamento entre vizinhos na avaliação de sua atuação no PSF.

Quanto aos médicos o elemento mais impactante é receber a visita de alguém que a comunidade reconhece como de grande status em sua "humilde" casa.

Quando a gente ia imaginar que o médico iria na nossa casa pra saber o que a gente tem... pegar menino no colo. (C)

Tem umas pessoas que vem em nossa casa, são maravilhosas né, que por sinal uma médica mesmo já veio em minha casa, que nunca aconteceu isso na vida da gente, e a gente ía pro médico aonde? Na cidade. Pegava ônibus cheio pra cidade. (B)

Os atributos mais referidos, quando avaliam sua relação com os médicos são escuta e gentileza.

Eles não são como estes médicos que olha pra gente, não pergunta nada e já dá a receita... eles têm paciência pra ouvir nossos problemas. (E)

O médico é gente boa, é que realmente ele foi até minha casa quando a minha filha tava passando mal. (C)

Às vezes o paciente não tem o medicamento, ela se interessa, ela vai e vê o medicamento. (B)

Essa relação parece associar-se a um novo perfil do médico que lhe é conferido pelos moradores a partir de uma valorização especial do que qualificam como uma pessoa generosa, disponível, comprometida e com uma boa capacidade de escuta. Convém ressaltar que, apesar de serem menos referidas, as enfermeiras também foram alvo de elogios.

M. (enfermeira) que ela tem uma mãozinha leve boa, não sei se é porque a gente é muito ami$g a$, eu tomei a vacina dos idosos. (A) 
Tem a enfermeira que também, que é superlegal com a gente. (B)

\section{A dimensão organizacional}

Ao contrário do que ocorreu com o componente relacional, o grau de satisfação quanto à dimensão organizacional é reduzido. De modo geral, a satisfação dos usuários em relação ao componente organizacional se associa grandemente à facilidade de acesso ao profissional e às ações de saúde quando comparada ao antigo modelo assistencial.

Tem médico pra ir na porta da pessoa, né! que no meu tempo, quando que se veria isso aí, né? Então, já que hoje nós temos o médico que vem com aquele cuidado todo (...) as agentes de saúde sempre estão freqüentemente conosco, então isso é maravilhoso, né? (C)

Por outro lado, a presença de uma equipe mínima nas unidades de saúde da família não supre a demanda da população assistida pelo programa, por pediatras, ginecologistas. As famílias queixam-se da inexistência de um(a) médico(a) obstetra que possa ocupar-se do parto das mulheres, ou de pediatras que atendam as suas crianças. Vale lembrar que a maioria das áreas cobertas pelo PSF tem uma baixa cobertura assistencial, inclusive no nível primário.

A única coisa que tá acontecendo aqui é o médico, só (...) requisição pra exames não tem, receituário não tem, medicação não tem, então o que é que tem. (A)

De uma maneira geral, as pessoas tendem a demandar que um maior número de ações médicas e paramédicas fiquem concentradas no nível local. Dessa forma, com relação ao acesso aos serviços, a ênfase é colocada naquelas atividades que reduziram o deslocamento das pessoas doentes ou com necessidade de um cuidado médico para outras regiões da cidade. Aí situa-se a valorização da iniciativa de realização de exames laboratoriais mais simples no próprio posto de saúde.

As queixas em relação ao aspecto organizacional remetem àquilo que ainda está insuficiente, precário ou inexistente. Na maioria das áreas investigadas persiste uma dificuldade no acesso a marcações de consulta e a exames de laboratório. Fica patente que o processo de referenciamento é precário e a cobertura, inclusive no nível primário, é baixa. As queixas situam-se em torno da dificuldade de acesso a especialistas, emergência, assistência dentária (situação um pouco melhor em E, onde consta um dentista na equipe mínima), da insuficiência de postos de realização de exames laboratoriais. Em caso de emergência ou de parto, essa situação se agrava devido ao custo de uma ambulância que possa fazer o transporte.

Tudo tem dificuldade. Eu fui fazer um exame de cabeça de meu menino, saí essa semana três vezes, saí três vezes quatro horas da manhã. (A)

Ambulância só tem uma, às vezes se procura essa ambulância e não se acha... (C)

Não, eu nem falo no posto de saúde, não tem pediatra. Se tem que marcar um exame de laboratório, tem que sair daqui 3:30, 4 horas da manhã porque senão não pega ficha. Então se tem que fazer exame de laboratório da criança, tem que sair daqui pra Salvador, porque aqui não tem que fazer. (D)

Quanto ao horário de atendimento da unidade muitos depoimentos referem-se à necessidade de atendimento em fins de semana e à noite (nenhuma das unidades funciona em regime de 24 horas por dia).

Se aí tivesse um atendimento no sábado, domingo e feriado, uma coisa assim... atendesse também emergência seria bom. (D)

Com relação à freqüência das visitas domiciliares, especialmente dos agentes, surgem queixas como estas: Eu tenho duas filhas, minhas filhas são pequenas, então tem que visitar minha casa diariamente ou então tem que visitar uma vez no mês. Leva dois, três meses sem ir na minha casa! (D)

O tempo de espera por consultas continua ainda muito elevado de acordo com os relatos dos usuários. A prática de acordar de madrugada para conseguir uma vaga diminuiu, mas não foi eliminada. Os usuários se queixam do número reduzido de fichas de atendimento, o que obriga as pessoas a saírem muito cedo de suas casas, arriscando-se a serem assaltadas ou agredidas.

Faz (exame) mas tem que acordar 3:30, 4 horas da manhã pra pegar ficha. São 20 fichas, cada uma ficha, uma criança, eu não acho justo não (...) (D)

Tem gente que ainda dorme na fila de meia noite até 7 horas da manhã para conseguir ficha. (C)

Assim mesmo, quando comparado com a situação anterior ao PSF, existe um reconhecimento de avanços nessa questão do tempo de espera.

É porque antigamente a gente acordava muito cedo, tinha vez que era um trabalho pra conse- 
guir marcar o cartão. Marcava pra trinta dias, se fosse esperar pra trinta dias, acho que a criança já tava ruim já. Então depois que eu peguei essas duas médicas, a saúde aqui, graças a Deus, melhorou. (E)

Com relação ao horário dos profissionais, a dificuldade com a presença diária do médico se reflete também no fortalecimento do recurso a alternativas caseiras, não de modo integrado e cooperativo, mas até hostil, denunciando um sentimento de desamparo e mesmo de perplexidade diante da lógica que governa a dinâmica demanda/atenção.

A minha (neta) mesmo estava com esse problema (respiratório) também, uma gripe, muita febre, levei aí em cima não tinha médico, não tinha nada, aí disse: ah, não tem médico hoje. (D)

Então, eu acho que vai da sorte de chegar lá e ter uma médica. Eu nunca dei sorte de chegare encontrar. (C)

Finalmente, a localização das Unidades de Saúde da Família é considerada na maioria dos municípios uma área de fácil acesso. Especialmente nas áreas onde se construiu uma unidade exclusivamente para este fim.

\section{A dimensão profissional}

A avaliação relativa à dimensão profissional do PSF é bastante positiva. São muito valorizados pelos usuários aspectos como tempo dispensado pelos profissionais seja na unidade, seja na comunidade; da eficácia das ações (com algumas limitações que veremos a seguir) e da qualidade ou competência das equipes e a disponibilidade. Os usuários reconhecem novidades positivas com o PSF, a exemplo das palestras sobre saúde materno-infantil, da assistência prénatal, da disponibilidade de tratamento odontológico (município $\mathrm{E}$ ).

Ainda que de forma fragmentada, os usuários do PSF identificam que as equipes realizam um tipo de cuidado que inverte o padrão de assistência tradicionalmente prestado pelo sistema oficial de saúde predominante. Entre as ações de saúde valorizadas pelos grupos focais estiveram as palestras realizadas para grupos de idosos e o acompanhamento pré-natal para gestantes.

A visita domiciliar é a atividade mais destacada pelos usuários.

Houve uma melhora, a gente tem aqui uma médica que vem ver a gente aqui, direto. A gente tem a visita do agente comunitário que antes não tinha. Agora a gente tem a agente comunitária que sempre tá pensando em nossos filhos, visitando nossa casa. (E)

A visita ao domicílio, de fato, implica uma nova forma de relação médico/paciente, diferente daquela estabelecida nos limites dos serviços mais formais de assistência, indicando uma conduta de maior qualidade do profissional de saúde. A visita domiciliar oferece também aos profissionais de saúde novas portas de entrada na vida cotidiana das pessoas e um maior poder de influência quanto às medidas e aos comportamentos de saúde a serem adotados pela população.

A qualidade do atendimento e a competência dos profissionais das equipes são destacadas entre os relatos.

E quanto ao atendimento no posto eu não tenho o que falar nada, toda vez que eu vou, sou bem atendida pela Dra. ..., Dra. ..., Dr. ... que é dentista, minha menina fez tratamento com ele, eu acho são umas pessoas legais. (E)

(...) como elas (as agentes) tava também me ajudando sabe. Elas tava ali olhando, como é que tá o cartão, se o menino vai vacinar hoje, se o menino tá faltando essa vacina. E eu sempre não tenho o que dizer. (A)

Observa-se ainda que a eficácia do programa se faz pela extensão da cobertura de certas ações de saúde a um maior número de pessoas e a uma parte da população que estava mesmo descoberta.

Preventivo, eu mesma nunca tinha feito, eu mesma com 42 anos nunca tinha feito um preventivo, fiz o meu aqui com elas. (C)

A implicação dos profissionais do PSF na busca de soluções para os seus problemas figura como um outro elemento muito valorizado pelos usuários.

Meu marido mesmo é doente. Dra. ... vai lá ver ele, conversa com ele, aconselha ele pra ele acompanhar o negócio do diabete. (D)

Eu tenho uma vizinha lá que o marido dela tava com problema lá, doente, e eles ficaram lá constantemente com eles. (A)

Como já foi dito anteriormente a unidade de saúde da família é referido geralmente como um "posto". Contudo, a população identifica que existe algo que os diferencia dos demais tendo o seu impacto sobre o cuidado à saúde da população reconhecido.O fragmento de narrativa referente à implantação do posto na área urbana ilustra bem essa opinião.

Discutiram o que era que a gente queria, o povo da comunidade, que não era um posto que nem o da URBIS, era um posto pras famílias, 
quando não agüentasse ir a ele, pra ter remédio que o pobre não tava tendo condição de comprar o remédio. Então foi discutida essas coisa, né. Graças a Deus, nós foi, demos apoio e aí o posto, Deus deu essa bênção, o posto veio pra rua de palha e depois inclusive agora na minha rua que eu moro, e tá sendo uma bênção esse posto aí. (E)

\section{A perspectiva dos profissionais}

Quando se considera o ponto de vista dos profissionais que atuam nas equipes do PSF, ressalta-se, de início, que eles falam a partir de outra perspectiva temporal (a lógica é mais a do atendimento e menos a da necessidade). As dimensões que se destacam em suas falas são o caráter preventivo e educativo do trabalho. Expressam um sentimento de satisfação notável com um trabalho pautado em ideais/empenho, motivação, que lhes permite o confronto com a realidade concreta e a abertura a experimentações através de novas linguagens.

Isso é um programa que prende muito a pessoa. Você se sente preso a isso aqui que acaba não querendo sair, não querendo sair porque gosta e por uma questão que já conseguiu implantar e tá implantando, tá fazendo... (Enfermeira C)

... a gente lida com a questão de todo um quadro social que está desfavorável (...) Por outro lado é um trabalho gratificante, porque a gente tá tentando ajudar a população em relação a isso, tentando introduzir um modelo diferente do que existe aí (...) (Médica D)

Em relação à dimensão cognitiva, os profissionais têm consciência da dificuldade da população de entender as regras de funcionamento do PSF e reconhecem que as oficinas realizadas no momento de implantação do PSF não são suficientes para sensibilizar e informar as pessoas sobre o programa. Alguns exploram os horários de sala de espera para informar a comunidade sobre as diretrizes e lógica de funcionamento do PSF.

... sempre que eu pego essas brechas, a gente está infiltrando PSF. Está colocando lá os cronogramas: 'gente, observe, está aqui na parede como é que a gente funciona'. Vacina é até quinta-feira. Por quê? Por isso, isso, isso... Então, eu acho que a sala de espera é um momento bom.

Quanto ao aspecto relacional, ao mesmo tempo em que reconhecem uma boa acolhida por parte da comunidade, defrontam-se, por vezes, com a resistência de grupos que reagem às estratégias de educação desenvolvidas pelos mesmos. Essa resistência revela, na maioria das vezes, o nível de tensão no qual essas pessoas vivem; tensão resultante de uma realidade social de extrema precariedade. Ao lado disso está o fato de que os profissionais de saúde, munidos de um saber sobre saúde reconhecido como o único legítimo, pode ser visto numa posição de superioridade em relação "àqueles que não têm educação nem conhecimento".

O que eu sinto assim é que eles acham que é uma invasão na vida deles quando nós colocamos sobre higiene, sobre saúde, quanto ao tipo de alimentação. Então eles acham que é uma ofensa. (Médica C)

A gente encontrava um pouco de resistência porque antigamente a gente só trabalhava com o curativo. Vendo o médico ir na casa sem ter nada, era uma surpresa. (ACS D)

Com relação ao aspecto organizacional, as equipes comentam avanços e dificuldades que se refletem nas falas dos usuários. $\mathrm{O}$ fato de o PSF atender a uma clientela adstrita a uma área determinada é visto pelas equipes como extremamente positivo, pois além de facilitar a criação de vínculo com a comunidade atendida, permite maior conhecimento da realidade com a qual se trabalha.

...é muito bom trabalhar com uma área delimitada porque você fica menos angustiada, você sabe que é com aquelas famílias que você vai trabalhar, você começa a conhecer o perfil da família, os problemas sociais que ela enfrenta e que dificuldades ela tem para resolver seus problemas de prevenção (...) fazer o vínculo é mais fácil. (Enfermeira B)

A dificuldade de refrear a demanda espontânea nas áreas atendidas configura-se como um nó crítico na realização das atividades da equipe.

...nós temos uma demanda espontânea muito grande, muito grande! Nós ainda temos fila quase toda manhã. Nós já tentamos várias maneiras: tanto agendamento semanal, sempre nas sextas-feiras; para o mês inteiro; para dois meses; mas a própria comunidade veio a nós e pediu " $a$ ficha igual lá no outro posto". (Médico, zona urbana E)

O sistema de referência e contra-referência, conforme informam as equipes em todos os municípios (a situação é melhor na zona urbana do município E), vem funcionando de modo informal, valendo-se, algumas vezes, de contatos pessoais dos membros das equipes com profissionais ligados a setores de média e alta complexidade, embora se constatem, já, alguns casos de pacientes que foram contra-referen- 
ciados satisfatoriamente (a exemplo do encaminhamento de pacientes psiquiátricos, outros de ginecologia, obstetrícia, dermatologia, etc). Muitas vezes, a dificuldade se dá na esfera política.

Um exemplo claro é o pré-natal. Vamos dizer, a gente se preocupa tanto em fazer um pré-natal de boa assistência, mas na hora do parto... a gente não tem referência. (Médico, zona urbana C)

Poder-se-ia dizer que, em uma das áreas do município D, o fato de haver a particularidade de que o Núcleo da Saúde da Família funcione ao lado de um Posto de Saúde onde trabalham médicos de diversas especialidades (cardiologista, oftalmologista, pediatra, etc.) constitui-se em uma vantagem no discurso da equipe de saúde. Constata-se que a presença dos especialistas funciona como uma retaguarda importante que facilita o sistema de referência e contra-referência e que, nesta área, contribui para que a equipe realize as múltiplas tarefas previstas na concepção do PSF.

No que tange a dimensão profissional, os profissionais reconhecem que a comunidade valoriza as ações diferenciadas realizadas pelas equipes do PSF, principalmente os atendimentos domiciliares e os grupos educativos (hipertensos, diabéticos, adolescentes, gestantes) além de atividades como planejamento familiar, prénatal e vacina. São destacadas experiências bemsucedidas, relacionadas à adesão ao tratamento de hipertensos, ao acompanhamento de gestantes e à vacina.

Porque a gente trabalha com a preventiva, então a gente só vai ver a longo prazo. Mas a gente já tá vendo muitas melhorias, muitas coisas já que fica surpreso. Na minha área mesmo, são 17 ou 18 gestantes, todas estão fazendo pré-natal (...) porque as pessoas não eram de sair de casa pra vir pro posto, porque as pessoas só vinham no posto quando estavam doentes, tinha que ir no hospital. (...). (Enfermeira, zona urbana A)

Por outro lado, reconhecem que existem queixas quanto à resolutividade do programa. Consideram que poderiam fazer mais se houvesse um processo mais eficaz na capacitação das equipes. Chamam atenção para o fato de que estão atuando em áreas onde a oferta de serviços é deficitária, faltando inclusive pediatras e ginecologistas.

As equipes enfrentam, também, problemas de infra-estrutura, material e equipamentos.

Achamos importante treinar o agente para verificar a pressão, anotar e encaminhar aqueles casos. Nós conseguimos os estetoscópios. Eles começaram a aprender, mas os estetoscópios eram de péssima qualidade. Descartável. (Médico, zona urbana D)

Não tem um carro disponivel pra gente se locomover. Aí nós vamos de ônibus (...) isso piora mais ainda quando a gente precisa deslocar um paciente de lá pra cá. (Enfermeira, zona rural A)

É uma ambulância para todo o município. A gente já teve caso de paciente padecer duas semanas lá, sem a gente conseguir trazer para internar. (Médica C)

O que se tem observado com a implantação das equipes de saúde nos diversos municípios é que o fato de ainda não haver uma quantidade suficiente de equipes para a demanda do município funciona como um fator de sobrecarga excessiva de trabalho para a equipe existente.

Na verdade, eu acho que quando a gente entra no programa do PSF, o trabalho dobra, tanto para o médico, quanto pra enfermeira, quanto para os agentes. É complicado. A cobrança é triplicada, é muito maior, e o salário continua o mesmo, talvez um pouquinho menor. (ACS falando sobre a mudança de sua função do PACS para o PSF)

Na prática, essa multiplicidade de atribuições dos vários profissionais tem-se mostrado um obstáculo ao anseio de substituir o modelo curativo por outro de características mais preventivas e de promoção de saúde. É sensível, apesar do nível de stress e de cansaço dos profissionais frente às demandas e adversidades enfrentadas, o nível de compromisso com a proposta.

\section{Considerações finais}

Constata-se um elevado grau de satisfação de usuários do Programa de Saúde da Família nas áreas estudadas, havendo uma clara associação dessa satisfação com os seguintes itens: maior acesso aos cuidados médicos, melhoria do nível de informação sobre o processo saúde-doença (situação de risco e proteção, cuidados básicos), a existência da visita domiciliar como elemento chave da prevenção e do acompanhamento. Do lado da população existe um reconhecimento do trabalho diferenciado por parte da equipe de saúde da família, e a imagem do médico que visita as pessoas nas suas residências, realizando um trabalho preventivo, aparece como paradigmática dessa mudança. Entre os aspectos negativos apontados pela população destaca-se a persistência das filas e a fragilidade no referenciamento para os níveis secundário e terciário da atenção. 
Observa-se que quanto maior o nível de informação do usuário sobre os objetivos, atividade e regras de funcionamento do PSF, maior o grau de satisfação em relação ao programa. $\mathrm{O}$ nível de informação está condicionado, ente outros aspectos, pelo grau de escolaridade do usuário e a eficácia das estratégias de comunicação e informação em saúde utilizada tanto no âmbito do PSF quanto do Sistema Municipal de Saúde.

Quanto aos profissionais da equipe do PSF, eles se surpreendem quando percebem que a "lógica da necessidade" não corresponde, na prá- tica, à "lógica do planejamento". O processo de implantação do PSF coincide, portanto, com um processo mais amplo de aprendizagem e compreensão acerca de uma nova perspectiva de atenção por parte da comunidade e dos profissionais de saúde. Essa compreensão se faz progressivamente na confrontação cotidiana entre um modelo e a prática desse modelo. Essa lógica não se muda por decreto e novas práticas de saúde envolvem a participação de um grande número de fatores intervenientes, dos quais poderíamos listar alguns.

\section{Referências bibliográficas}

Atkinson SJ 1993. Anthropology in research on the quality of health services. Cadernos de Saúde Pública 9(3): 283-299.

Barros FC \& Victora CG 1996. Saúde materno-infantil em Pelotas, Rio Grande do Sul, Brasil: principais conclusões da comparação dos estudos das coortes de 1982 e 1993. Cadernos de Saúde Pública 12(1):87-92.

Bastos AC 1994. Modos de partilhar: a inserção da criança na vida cotidiana da família: um estudo de casos. Tese de doutorado. Universidade de Brasília, Brasília, 248pp.

Costa JSD, Victora CG, Barros FC, Halpern R, Horta BL \& Manzolli P 1996. Assistência médica materno-infantil em duas coortes de base populacional no Sul do Brasil: tendências e diferenciais. Cadernos de Saúde Pública 12(1):59-66.

Donabedian A 1980. Exploration in quality assessment and monitoring. Vol.1 - The definition of quality and approaches to its assessment. Ann Arbor, University of Michigan, Michigan.

Favaro P \& Ferris LE 1991. Program evaluation with limited fiscal and human resources. In AJ Love (ed.). Evaluation methods sourcebook. Société Canadienne d'Evaluation, Ottawa. Gattinara BC, Ibacache J, Puente CT, Giaconi J \& Caprara A 1995. Percepción de la comunidad acerca de la calidad de los servicios de salud en los Distritos Norte e Ichilo, Bolivia. Cadernos de Saúde Pública 11(3):425-438.
Paim JS 1999. A Reforma Sanitária e os modelos assistenciais. In Rouquayrol MZ. Epidemiologia \& Saúde, MEDSI.

Pascoe GC 1983. Patient satisfaction in primary health care: a literature review and analysis. Evaluation and Program Planning 6:185-210.

Prévost A, Fafard A \& Nadeau MA (1998). La mesure de la satisfaction des usagers dans le domaine de la santé et des services sociaux: l'experience de la Régie Régionale Chadière-Appalaches. The Canadian Journal of Program Evaluation 13(1):1-23.

Schraiber LB, Nemes MBI, Gonçalves RBM (org.). 1996. Saúde do adulto. Hucitec, São Paulo.

Trad LAB et al. 1998. A construção social da estratégia de saúde da família: condições, sujeitos e contextos. PNEPG, CNPq.

Williams B 1994. Patient satisfaction: a valid concept? Social Science and Medicine 38(4):509-51.

Ware JE, Snyder MK, Wright WR \& Davies AR 1983. Defining and measuring patient satisfaction with medical care. Evaluation and Program Planning 6: 247-263.

Artigo apresentado em 18/5/2002

Versão final apresentada em 6/7/2002

Aprovado em 21/8/2002 